(2) Open Access Full Text Article

LETTER

\title{
How should pediatric communication skills be taught? The medical student perspective
}

This article was published in the following Dove Press journal:

Advances in Medical Education and Practice

17 February 2017

Number of times this article has been viewed

\section{Alysha Bhatti \\ Midhat Ahmed \\ Faculty of Medicine, Imperial College London, London, UK}

\section{Dear editor}

We thank Frost et $\mathrm{al}^{1}$ for their article evaluating a scenario-based pediatric communication skills program for medical students at Cardiff University. The General Medical Council states that "effective communication between doctors and young people is essential to the provision of good care"; yet medical students are relatively underexposed to the pediatric clinical arena. ${ }^{2}$ Thus, we agree with the authors that undergraduate medical school curricula must place greater emphasis on garnering the unique skills of pediatric communication.

We commend the authors' use of the Calgary-Cambridge Model in designing the program, ${ }^{3,4}$ as it gives great importance to biopsychosocial aspects of presentation, thus encouraging a holistic approach to patient care while also allowing for the flexibility that is integral to pediatric practice. Furthermore, the use of a model already familiar to medical students may help instill confidence when approaching unfamiliar clinical scenarios.

While the authors envisage that future sessions will be taught exclusively by pediatricians, in our opinion, general practitioners were well positioned as facilitators. Given that patients under 15 years of age account for a quarter of consultations in general practice, ${ }^{5}$ general practitioners are experienced in working with both children and adults, and therefore may be better placed than pediatricians in helping medical students transition from a primarily adult environment to a pediatric one.

We would like to highlight that while a majority of the students surveyed in the study found the session "interesting", only $43 \%$ felt "more confident communicating with children and their parents after the session". ${ }^{1}$ One potential explanation for this, acknowledged by Frost et al, ${ }^{1}$ is that no formal teaching of pediatric communication skills was provided. At Imperial College School of Medicine, fifth-year students completing pediatric placements at different hospital sites attend weekly centralized pediatric consultation skills teaching. In these lecture-based sessions, the approach to manage common as well as more challenging pediatric consultations, such as child safeguarding, is discussed. As fifth-year medical students having completed our pediatric placement, we note that exposure to clinical scenarios may be variable, and thus have benefitted from centralized pediatric consultation skills teaching that has provided us with frameworks for dealing with scenarios we may otherwise not have encountered. In summary, we feel that in addition to scenario-based small group sessions, formal lecture-based teaching of pediatric communication skills is valuable.
Faculty of Medicine, Imperial College

London, Prince Consort Road,

Kensington, London, SW7 2BB, UK

Email ab6412@imperial.ac.uk 
A further avenue to explore is that of simulation training, as we feel that this educational strategy is currently underused in undergraduate pediatric teaching. Exposure to simulated pediatric emergencies such as acute asthma attacks, anaphylaxis, or status epilepticus would not only cement clinical knowledge but also assist medical students in developing teamwork abilities and raise their awareness of human factors. Successful management of such scenarios requires effective communication between colleagues, the patient, and relatives alike. Hence, subsequent structured debriefing and feedback would allow medical students to hone these communication skills.

In our experience, the most useful teaching received involved pediatrician-led assessment and feedback of communication skills in student consultations with real patients, echoing a desire that many students expressed in the study survey. Regular and formal assessment of this nature enables students to learn how to communicate with real children and ensures sustainability of competencies achieved. Furthermore, it permits evaluation of the efficacy of teaching methods, thus allowing improvements to be made.

In conclusion, we believe that a combination of formal, small group, and simulation teaching would be most effective in helping medical students to embed key skills in pediatric communication. This variety of methods caters to different learning styles, as well as striking a balance between theoretical and practical learning. As with the discipline of medicine in general, there is no substitute for engaging in real-life consultations with both child and parent, and we believe teaching and assessment should mirror this as far as possible.

\section{Disclosure}

The authors report no conflicts of interest in this communication.

\section{References}

1. Frost K, Metcalf E, Brooks R, Kinnersley P, Greenwood S, Powell C. Teaching pediatric communication skills to medical students. Adv Med Educ Pract. 2015;6:35-43.

2. General Medical Council. 0-18 years: guidance for all doctors, 2007. Available from: http://www.gmc-uk.org/static/documents/content/0_18_ years.pdf. Accessed December 19, 2016.

3. Kurtz S, Silverman J, Benson J, Draper J. Marrying content and process in clinical method teaching: enhancing the Calgary-Cambridge guides. Acad Med. 2003;78(8):802-809.

4. Kurtz S, Silverman J. The Calgary Cambridge Referenced Observation Guides: an aid to defining the curriculum and organizing the teaching in communication training programs. Med Educ. 1996;30(2):83-89.

5. Royal College of General Practitioners. Care of Children and Young People, 2012. Available from: http://www.gmcuk.org/RCGP_Curriculum_3.04_Children_and_Young_People.pdf_49502510.pdf. Accessed December 19, 2016.

Dove Medical Press encourages responsible, free and frank academic debate. The content of the Advances in Medical Education and Practice 'letters to the editor' section does not necessarily represent the views of Dove Medical Press, its officers, agents, employees, related entities or the Advances in Medical Education and Practice editors. While all reasonable steps have been taken to confirm the content of each letter, Dove Medical Press accepts no liability in respect of the content of any letter, nor is it responsible for the content and accuracy of any letter to the editor.

\section{Publish your work in this journal}

Advances in Medical Education and Practice is an international, peerreviewed, open access journal that aims to present and publish research on Medical Education covering medical, dental, nursing and allied health care professional education. The journal covers undergraduate education, postgraduate training and continuing medical education including emerging trends and innovative models linking education, research, and health care services. The manuscript management system is completely online and includes a very quick and fair peer-review system. Visit http://www.dovepress.com/testimonials.php to read real quotes from published authors. 